\title{
Gender Decision
}

\author{
Monique Radeau \\ Université Libre de Bruxelles \& FNRS, Brussels, Belgium
}

Jos J.A. van Berkum

Max-Planck-Institute for Psycholinguistics, Nijmegen, The Netherlands

In languages in which nouns have a grammatical gender, word recognition can be estimated by gender decision response times. Although gender decision has yet to be used extensively, it has proved sensitive to several factors that have been shown to affect lexical access. The task is not restricted to spoken language but can be used with linguistic information from other sensory modalities.

\section{Issues Addressed}

Lexical access in spoken and written (regular and braille) word recognition.

\section{First Uses}

Deutsch and Wijnen (1985).

\section{Description}

Two variants were used by Deutsch and Wijnen (1985): gender assignment and gender verification. In gender assignment, the subject's task is to indicate the grammatical gender of a noun. This task has also been referred to as "gender monitoring" by Bates et al. (1995). In gender verification, a noun is presented, together with a word that marks gender (e.g. article,

Requests for reprints should be addressed to Monique Radeau, Laboratoire de Psychologie Expérimentale, Université Libre de Bruxelles, C.P. 191, Avenue F. Roosevelt 50, B-1050 Brussels, Belgium. E-mail: moradeau@ulb.ac.be

The work of M.R. on gender decision has been supported by the Ministry of Education of the Belgian French-Speaking Community (" 'Concerted research action' language processing in different modalities: Comparative approaches", and "The structure of the mental lexicon: A multilevel approach to the multiple representations of words") and by the Belgian Fonds National de la Recherche Scientifique (Convention No. 8.4514.95). We would like to thank Elizabeth Bates and Alain Desrochers for their comments during the review process. 
adjective, etc.); the subject has to decide whether they agree in gender or not. This task was also used by de Ruiter (1992) in Dutch. The response is generally given manually by key-pressing but can also be given vocally. Vocal responses were used by Desrochers, Paivio and Desrochers (1989) and Desrochers and Paivio (1990) in studies devoted to written word recognition.

\section{Stimuli}

Nouns that have unambiguous grammatical gender. These nouns exist in many languages, including several Indo-European languages that have two or three genders (e.g. feminine or masculine in French, Italian, Spanish; neuter or non-neuter in Dutch; feminine, masculine or neuter in German, Serbo-Croatian, Russian, Icelandic). Other languages have even more genders (e.g. up to 20 in Bantu languages; Corbett, 1991).

\section{Dependent Variables}

1. Response latencies.

2. Errors.

\section{Independent Variables}

The same as with most of the other tasks, as well as variables specifically related to gender. With isolated words, any variable that can influence lexical access; for instance, word duration, number of syllables, word frequency, age of acquisition of the word, frequency and density of the lexical neighbourhood, uniqueness point position (UP), phonological markings for gender, semantic variables (e.g. concreteness, humanness, semantic gender). With word or sentence-like contexts, different kinds of context variables (e.g. semantic, formal, gender relatedness) that have been considered in priming studies.

\section{Analysis Issues}

The same issues as with most other tasks (e.g. lexical decision, semantic classification, single word shadowing).

\section{Effects Found with Paradigm}

1. Effect of word duration before UP (the UP is the point from word onset at which only one candidate remains in the cohort of possible words; Marslen-Wilson \& Welsh, 1978) 
Shown by: Radeau, Mousty and Bertelson (1989, French); Bates et al. (1995, Italian).

Not found by: de Ruiter (1992, Dutch).

2. Effect of word duration, word duration after UP, number of syllables Shown by: Bates et al. (1995, Italian).

3. Interaction between UP effect and articulation rate. The UP effect increases when the rate is slow and disappears when the rate is fast, i.e. close to that of spontaneous speech

Shown by: Radeau, Mousty and Pasdeloup (1994, French, natural and synthetic speech).

4. Effect of phonological transparency of gender marking on word endings Shown by: Bates et al. (1995, Italian).

5. Gender priming

Shown by: Deutsch and Wijnen (1985, Dutch, article prime-noun target); Bates, Devescovi, Hernandez and Pizzamiglio (1996, Italian, adjective prime-noun target).

6. Gender asymmetry effect (responses are faster and more accurate for one gender than for another)

Shown by: Deutsch and Wijnen (1985, Dutch); Bates et al. (1995, Italian).

\section{Design Issues}

1. Manual vs oral response. In the case of manual responses, handedness, gender dominance in the language under study and gender-to-button allocation have to be included in the design (van Berkum, 1996; see Potential Artifacts).

2. In gender assignment, type of response labelling, i.e. abstract gender indication (masculine, feminine, neuter, non-neuter) or article indication. For visual French words, faster responses were obtained with labels "un" and "une" than "masculin" and "feminin" (Desrochers et al., 1989; Desrochers \& Paivio, 1990; Desrochers \& Brabant, 1995). In the case of article indication, the type of article sometimes matters. In French and Italian, there are two forms of singular definite and indefinite articles (e.g. "un", "une", "le", "la" in French or "una", "uno", "il", "la" in Italian). When definite articles are followed by a word beginning with a vowel, there is vowel suppression ("l'arbre", "l'elefante") so that these articles no longer mark gender. The problem can be avoided by using the definite articles together with nouns beginning with a consonant (see Bates et al., 1995) or by using indefinite articles.

3. Distribution of the different genders. About equal in some languages (e.g. about 5:4 for masculine and feminine nouns in French; Content, 
Mousty, \& Radeau, 1990), but less so in others (e.g. about 3:1 for non-neuter and neuter nouns in Dutch; van Berkum, 1996).

\section{Validity}

1. Effect of word duration before UP also found with the phonemic restoration illusion (Samuel, 1987), the phoneme detection task (Frauenfelder, Segui, \& Dijkstra, 1990) and single word shadowing (Radeau \& Morais, 1990; Bates et al., 1995).

2. Effect of word duration and word duration after UP also found with the phoneme detection task (Frauenfelder et al., 1990) and with single word shadowing (Bates et al., 1995).

3. Interaction between UP effect and articulation rate also found with single word shadowing (Radeau, Mousty, Morais, \& Bertelson, in prep., natural and synthetic speech).

4. Gender priming also found with gating and lexical decision (Grosjean et al., 1994, French, article prime-noun target) and with single word shadowing and grammaticality judgement (Bates et al., 1996, adjective prime-noun target).

5. Gender asymmetry effect also found with single word shadowing (Bates et al., 1995).

\section{Advantages}

1. Easy to use.

2. Can also be used in sensory modalities other than auditory:

Visual modality: used with printed words to investigate the role of different variables, including UP position (Radeau et al., 1992), phonological transparency of gender marking (Desrochers et al., 1989; Desrochers \& Paivio, 1990), word frequency and formal priming (A. Desrochers, pers. comm.), humanness semantic dimension (Desrochers \& Brabant, 1995). Also used with pictures to study lexical access and gender retrieval during speech production (Jescheniak \& Levelt, 1994; van Berkum, 1996).

Tactile modality: used with braille words in the blind to investigate the role of UP position (Bertelson, Mousty, \& Radeau, 1992).

3. Allows the study of word recognition in its natural linguistic-syntactic context.

\section{Potential Artifacts}

1. Stimulus properties that provide gender information (e.g. phonological cues in Italian, French) may be used to derive, rather than retrieve, gender (van Berkum, 1996). See, for exam ple, effects of phonological cues obtained 
in French for word endings (Tucker, Lambert, Rigault, \& Segalowitz, 1968; Radeau et al., 1989) and for word beginnings (Tucker et al., 1968) in a task that consists of guessing the gender of spoken nonwords including these endings or beginnings. As regards the involvement of a phonological strategy, see, for example, the effect of phonological transparency of word ending found with gender decision but not with single word shadowing in Italian (Bates et al., 1995). However, for French, no significant correlation was found between RTs to the experimental words and the predictive values of their endings (Radeau et al., 1989).

2. With manual response, there is the possibility of complex interaction between handedness, response allocation and gender dominance in the language. See van Berkum's finding of a facilitatory effect when the neuter response was under the dominant hand, but of an inhibitory effect with the opposite key arrangement (van Berkum, 1996, experiment 2, chapter 4).

\section{Problems}

1. Restricted to languages with a grammatical gender system.

2. Materials restricted to words that have gender (nouns).

3. Sensitive to strategic contaminants.

\section{Uses with Other Populations}

Has been used with blind people to study the effect of UP position in spoken and braille word recognition (Bertelson et al., 1992). Can also be used with children and brain-damaged patients.

\section{Other Comments}

Is especially appropriate when a lexical decision task cannot be used because nonwords have to be avoided, or when one is particularly interested in the retrieval of a word's syntactic properties.

\section{References}

Bates, E., Devescovi, A., Hernandez, A., \& Pizzamiglio, L. (1996). Gender priming in Italian. Perception and Psychophysics, 58, 992-1004.

Bates, E., Devescovi, A., Pizzamiglio, L., D’Amico, S., \& Hernandez, A. (1995). Gender and lexical access in Italian. Perception and Psychophysics, 57, 847-862.

Bertelson, P., Mousty, P., \& Radeau, M. (1992). The time course of Braille word recognition. Journal of Experimental Psychology: Learning, Memory and Cognition, 18, 284-297.

Content, A., Mousty, P., \& Radeau, M. (1990). BRULEX: Une base de données lexicales informatisée pour le français écrit et parlé. L'Année Psychologique, 90, 551-566.

Corbett, G.G. (1991). Gender. Cambridge: Cambridge University Press.

de Ruiter, J.P. (1992). Predicting and measuring the moment of auditory word recognition. Unpublished thesis, Max-Planck-Institute for Psycholinguistics, Nijmegen. 
Desrochers, A., \& Brabant, M. (1995). Interaction entre facteurs phonologiques et sémantiques dans une épreuve de catégorisation lexicale. Revue Canadienne de Psychologie Expérimentale, 49, 240-262.

Desrochers, A., \& Paivio, A. (1990). Le phonème initial des noms inanimés et son effet sur l'identification du genre grammatical. Canadian Journal of Psychology, 44, 44-57.

Desrochers, A., Paivio, A., \& Desrochers, S. (1989). L'effet de la fréquence d'usage des noms inanimés et de la valeur prédictive de leur terminaison sur l'identification du genre grammatical. Revue Canadienne de Psychologie, 43, 62-73.

Deutsch, W., \& Wijnen, F. (1985). The article's noun and the noun's article: Explorations into the representation and access of linguistic gender in Dutch. Linguistics, 23, 793-810.

Frauenfelder, U., Segui, J., \& Dijkstra, T. (1990). Lexical effects in phonemic processing: Facilitatory or inhibitory? Journal of Experimental Psychology: Human Perception and Performance, 16, 77-91.

Grosjean, F., Dommergues, J.-Y., Cornu, E., Guillelmon, D., \& Besson, C. (1994). The gender marking effect in spoken word recognition. Perception and Psychophysics, 56, 590-598.

Jescheniak, J.-D., \& Levelt, W.J.M. (1994). Word frequency effects in speech production. Journal of Experimental Psychology: Learning, Memory and Cognition, 20, 824-843.

Marslen-Wilson, W.D., \& Welsh, A. (1978). Processing interactions and lexical access during word recognition in continuous speech. Cognitive Psychology, 10, 29-63.

Radeau, M., \& Morais, J. (1990). The uniqueness point effect in the shadowing of spoken words. Speech Communication, 9, 155-164.

Radeau, M., Mousty, P., \& Bertelson, P. (1989). The effect of the uniqueness point in spoken-word recognition. Psychological Research, 51, 123-128.

Radeau, M., Morais, J., Mousty, P., Saerens, M., \& Bertelson, P. (1992). A listener's investigation of printed word processing. Journal of Experimental Psychology: Human Perception and Performance, 18, 861-871.

Radeau, M., Mousty, P., \& Pasdeloup, V. (1994). L'effet du débit de parole sur le rôle du point d'unicité. Actes des XXmes journées d'étude sur la parole, 529-534.

Radeau, M., Mousty, P., Morais, J., \& Bertelson, P. (in prep.). The effect of articulation rate on the role of the uniqueness point in spoken word recognition.

Samuel, A.G. (1987). Lexical uniqueness effects of phonemic restoration. Journal of Memory and Language, 26, 36-56.

Tucker, G.R., Lambert, W.E., Rigault, A., \& Segalowitz, N. (1968). A psychological investigation of French speakers' skill with grammatical gender. Journal of Verbal Learning and Verbal Behavior, 7, 312-316.

van Berkum, J.J.A. (1996). The psycholinguistics of grammatical gender: Studies in language comprehension and production. Nijmegen: Nijmegen University Press. 